\title{
Low-cost, disposable colourimetric sensors for metal ions detection
}

\author{
Giancarla Alberti ${ }^{*}$ D, Camilla Zanoni, Lisa Rita Magnaghi and Raffaela Biesuz
}

\begin{abstract}
In this work, two colourimetric sensors for metal ions detection are presented. The devices are obtained by fixing two classical dyes, Eriochrome Black T (EBT) and 1-(2-pyridylazo)-2-naphthol (PAN), on the commercial paper sheet "Colour Catcher ${ }^{\oplus "}$ (here named under the acronym CC) generally used in the washing machine to prevent colour run problems. The devices are optical sensors, since the indicator dye, fixed on the solid material, changes its spectral properties (colour and hence UV-vis spectrum) upon contact with the metal ion solution. We used the partial least squares (PLS) regression for obtaining the relationship between the metal ion content and the UV-vis spectrum change of each sensor.
\end{abstract}

Keywords: Dyes, Colourimetric sensors, Solid-phase spectroscopy, Metal ion detection, Partial least squares (PLS) regression

\section{Introduction}

In the last decades, the detection of actually toxic metal ions in the environment, food, biological samples, and commonly used items has grown the interest due to their ecosystems and human health adverse effects.

It has been recognized for years the role of metal ions in biological systems. It is well known that some metals are essentials, but others are toxic. Some are hypoallergenic such as nickel and silver, while others are essential to all forms of life, for example, iron and zinc.

Although many metals are abundantly present in the earth's crust, environmental contamination and human exposure arise from several anthropogenic activities. Environmental pollution can also occur through metal corrosion, atmospheric deposition, soil erosion of metal ions and leaching of heavy metals, sediment re-suspension, and metal evaporation from water resources to soil and ground waters.

Consequently, fast and accurate detection of metal ions has become a critical issue. Many analytical techniques are being applied, in particular, atomic absorption

\footnotetext{
* Correspondence: galberti@unipv.it

Dipartimento di Chimica, Università degli Studi di Pavia, via Taramelli 12, 27100 Pavia, Italy
}

spectroscopy (AAS), atomic fluorescence spectroscopy (AFS), inductively coupled plasma-mass spectroscopy (ICP-MS), etc. All these techniques are expensive, laborious, and time-consuming. They require a well-trained analyst, often they need a pre-treatment step of the samples, and sometimes cleanroom facilities (Sharma 2016).

Conversely, optical sensors are particularly friendly, thanks to their simple realization, affordability, and ease of use; they also allow in situ and real-time monitoring.

In particular, disposable sensors are very versatile and allow remote and continuous monitoring. They are designed to be one-shot, do not experience the so-called memory effects, and generally, they do not require cleaning between measurements. The recent studies propose ionophore-based chemical sensors, prepared by fixing different types of reagents, such as chromogenic, fluorescent, and ionophoric compounds on a solid support, like polymer, filter paper, or a thin layer of metals (Duarte 2015; Kaur 2018; Ng 2010; Steimberg 2003; Vuković 2012). Recently, optical platforms based on nanomaterials have been developed for the detection of several metal ions. Incorporation of nanomaterials and nanostructures into optical sensors can improve the performance of devices significantly, in terms of sensitivity, selectivity, multiplexed detection capability, portability,

\section{Springer Open}

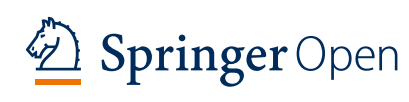

(c) The Author(s). 2020 Open Access This article is licensed under a Creative Commons Attribution 4.0 International License, which permits use, sharing, adaptation, distribution and reproduction in any medium or format, as long as you give appropriate credit to the original author(s) and the source, provide a link to the Creative Commons licence, and indicate if changes were made. The images or other third party material in this article are included in the article's Creative Commons licence, unless indicated otherwise in a credit line to the material. If material is not included in the article's Creative Commons licence and your intended use is not permitted by statutory regulation or exceeds the permitted use, you will need to obtain permission directly from the copyright holder. To view a copy of this licence, visit http://creativecommons.org/licenses/by/4.0/. 
and on-site detection ability (Berlina 2019; Gogoi 2015; Li 2013; Maruthupandy 2017; Ullah 2018; Yarur 2019). The most described are fluorescent, surface-enhanced Raman scattering (SERS), and surface plasmon resonance (SPR) sensors.

Hybrid sensing materials have emerged as innovative optical probes; they were prepared by the covalent grafting of organic fluorescent molecules onto inorganic supports. Considerable efforts have been dedicated to developing effective and innovative approaches for the design and synthesis of hybrid sensing materials in order to obtain high performance for ion detection and removal (Sun 2016).

Photonic crystals can reflect light and have emerged as attractive materials for developing optical sensors. In particular, hydrogel-based photonic crystals are proposed to design various metal ion sensors (Moirangthem 2016).

If compared with electrochemical sensors, most optochemical devices show significant advantages such as the easy miniaturization process and the extensive broad of applications.

We have already developed optical devices for metal ions, using several different solid materials, for instance, chelating resins, triacetylcellulose membrane, and filter paper. Specifically for Fe(III), we studied different strategies, synthesizing polymers or linking each different selective ligands to natural or commercially available supports (Alberti 2016; Biesuz 2014; Alberti 2015; Vallejos 2016; Biesuz 2018).

In the present research, we decided to move through a new approach, developing colourimetric sensors with a simple preparation strategy, standard reagents, and inexpensive items.

These devices are obtained by sorption of two conventional dyes, on a commercial material: the Colour Catcher, a product of the washing powder market, distributed in Italy by Grey, a partner of the Henkel company, and in England by Dylon (https://www.dylon.com. my/; https://www.casahenkel.it/brand/grey/grey-acchiappacolore.html). This product is generally used in the washing machine to prevent colour run problems. It was chosen as excellent and cheap support for the selected dyes; thanks to its properties, the ease in finding it, and the low cost (it costs around $€ 0.2$ per sheet of $11 \times 25$ $\mathrm{cm})$.

Among different metal ions of environmental and biological interest, we focused on some divalent cations. In particular, we prepared two different colourimetric devices, selecting the following dyes:

- Eriochrome Black T (EBT), for $\mathrm{Ca}(\mathrm{II}), \mathrm{Mg}(\mathrm{II})$, and water hardness determination;

- 1-(2-Pyridylazo)-2-naphthol (PAN), for Co(II), $\mathrm{Ni}(\mathrm{II})$, and $\mathrm{Zn}(\mathrm{II})$; so obtaining their respective sensors named EBT-CC and PAN-CC.
Before applying the new devices as optical sensors, we characterized the solid phases and studied their sorption properties.

To test the sensing properties of the optodes toward the cations, we registered the UV-vis spectra of the device after equilibration with a single analyte or multianalyte solutions.

The multivariate regression PLS (partial least squares regression) is applied to correlate the analyte content with the UV-vis spectrum change of each sensor.

PLS regression is a technique that combines features from principal component analysis and multiple regression. The procedure of PLS is described in detail by Gerlach and Kowalski (Gerlach 1979). Due to its ability to extract information, nowadays, PLS regression based on spectroscopic data is widely used.

PLS is commonly applied to the simultaneous analysis of two datasets, such as spectra and concentration. Based on several factors (latent variables), PLS builds the linear model $y=X \cdot b$, which allows the prediction of concentration $(y)$ from measured spectra $(X)$; $b$ contains the regression coefficients obtained during the calibration step.

In detail, $\mathrm{X}$ is the $n \times m$ matrix of measured responses obtained from spectrophotometry, where $n$ is the number of samples and $m$ is the number of wavelengths of the whole spectrum.

$y$ is the $n \times c$ concentration matrix of $c$ analytes. $b$ is the $n \times c$ vector of regression coefficients, which is solved for when PLS is calibrated. Knowing $b$, the calibrated model can predict new $y$ concentrations from the measured $X$ spectra of unknown samples (HassaninejadDarzi 2016).

\section{Experimental}

\section{Chemicals and apparatus}

All reagents were of analytical grade; MilliQ water was used throughout. Calcium, cobalt, copper, magnesium, nickel, and zinc standard solutions were obtained by dilution of $1000 \mathrm{mg} / \mathrm{L}$ ICP standards (Sigma-Aldrich, Italy). Eriochrome ${ }^{\circ}$ Black T (EBT) and 1-(2-pyridylazo)2-naphthol (PAN), in powder form, were obtained by Sigma-Aldrich, Italy.

Colour Catcher (hereafter CC) was bought in a typical Italian supermarket.

FT-IR spectra were obtained on a Nicolet FT-IR iS10 spectrometer (Nicolet, Madison, WI, USA) equipped with an ATR (attenuated total reflectance) sampling accessory (Smart ITR with ZnSe plate) by co-adding 256 scans in the $4000-600 \mathrm{~cm}^{-1}$ ranged at $4 \mathrm{~cm}^{-1}$ resolution. SEM measurements and energy dispersive microanalysis were performed using a Zeiss EVO MA10 (Carl Zeiss, Oberkochen, Germany) coupled with an EDS detector (X-max $50 \mathrm{~mm}^{2}$ Oxford Instruments, Oxford, $\mathrm{UK})$ on as-prepared samples deposited on a $\mathrm{C}$ bi- 
adhesive layer. An energy-dispersive X-ray spectroscopy (EDS)-mapping (an EDAX Inc., USA) and an EDS Genesis program, installed on the SEM instrument, were used to analyze the elemental components of the sample.

ICP-OES analysis of metal ion solutions were performed by a PerkinElmer Optima 3300 DV (dual view) (Perkin Elmer, Milan, Italy), instrument.

A Jasco V-750 spectrophotometer recorded the UV-vis spectra of each sensor after equilibration. The instrument is equipped with an FLH-740 Film Holder (Jasco Europe S.R.L, Lecco, Italy) and a homemade holder designed to make the spectrum acquisition easy and quick. This holder was printed on a project of Simone Marchetti, a PhD student in our department, with the support and the facilities of the lab 3D@UniPV, Virtual Modelling and Additive Manufacturing for Advanced Materials (University of Pavia, Italy).

\section{Characterization of the CC product}

The Colour Catcher's success is due to the ability to preventing colours run in the washing machine. The $\mathrm{CC}$ sheet exhibits sequestration properties towards molecules and ions when released by clothes, even in the presence of surfactants and fabric softeners.

The sheet appears similar to textile, and it is pretty rigid ( $96 \%$ of dry substance), but once wetted, it becomes soft. Often tissue dyes are ionic, so we tested the Colour Catcher sheet as an ion exchange device. A Colour Catcher package contains 16 sheets, of the same dimension $11 \times 25 \mathrm{~cm}$, and it costs about $3 / 4 €$. For our purposes, the CC product was employed as delivered.

The bare material was characterized by ATR-IR and EDX spectroscopies and by SEM.

\section{Preparation of EBT-CC and PAN-CC sensors}

Each dye was immobilized on the $\mathrm{CC}$ according to an ion exchange process. The thereby obtained materials were denoted hereafter EBT-CC and PAN-CC, respectively.

For practical reasons, one original CC sheet was cut in $2 \times 2 \mathrm{~cm}$ pieces, of about $0.03 \mathrm{~g}$.

The optode was obtained by contacting a piece of the $\mathrm{CC}$ sheet with $10 \mathrm{~mL}$ of an aqueous solution of a proper concentration of each dye for about $3 \mathrm{~h}$. After rinsing with MilliQ water, the product obtained was stable for days.

Kinetic profiles and isotherms of the sorption of dyes on CC We performed kinetic profiles and sorption isotherms by using a discontinuous procedure. In 10 independent plastic sealed vessels of $50 \mathrm{~mL}, \mathrm{CC}$ bare pieces of $2 \times 2$ $\mathrm{cm}$ were put in contact with $10 \mathrm{~mL}$ of solution, at a suitable $\mathrm{pH}$, and containing each dye at a known concentration. The sealed vessels were left gently stirring on a shaking plate at constant room temperature. At a given time for kinetic experiments, or after the equilibration time for sorption isotherms, the stirring was interrupted, and a sample of the solution phase was analyzed for the ligand content by UV-vis spectrometry. The amount of sorbed ligand, $q\left(\mathrm{mmol} \mathrm{g}^{-1}\right)$, was determined by difference from the total.

\section{EBT-CC and PAN-CC as sensors: application of the multivariate regression PLS}

As the central part of the work, we developed models for assessing, in unknown samples, the concentration of the tested analytes. We applied the chemometric tool PLS (partial least squares regression) for reaching the goal. For each sensor, we submitted to the PLS analysis full UV-vis spectra of the solid phase after equilibration with the analyte solutions. To plan the experiments required to create the PLS model (the so-called training set ), we referred to a suitable experimental design (Brerenton 1997) The regression model is first tested with a crossvalidated procedure on the training set, and then, on an external data set, called the test set. Cross-validation is any of various similar model validation techniques for assessing how the results of a statistical analysis will extrapolate to an independent data set. It is generally used in settings where the aim is prediction, and one needs to estimate how accurate is the predictive model. The goal of cross-validation is to check the model's ability to predict a new dataset, in order to avoid problems like overfitting or selection bias and to give an insight on how the model will generalize to an independent and unknown dataset (Kohavi 1995).

The method of cross-validation here applied is leave-one-out cross-validation (LOOCV). This method is performed by estimating $n$ calibration models, where each of the $n$ calibration samples is left out one at a time in turn. The resulting calibration models are then used to estimate the sample left out, which acts as an independent validation sample and provides an independent prediction of each $y_{i}$ value, $\hat{y}_{i}$, where the notation $i$ indicates that the $i$ th sample was left out during model estimation. The process is repeated until all of the calibration samples have been left out (Gemperline 2006).

We choose to analyze as external data set some actual samples with a known content of the analytes. The model was judged valid if the prediction error on the concentration was around $10-15 \%$.

For the PLS data treatment, we use the R-based chemometric freeware CAT (Chemometric Agile Tool) developed by the Group of Chemometrics of the Italian Chemical Society (http://gruppochemiometria.it/index. $\mathrm{php} /$ software) 


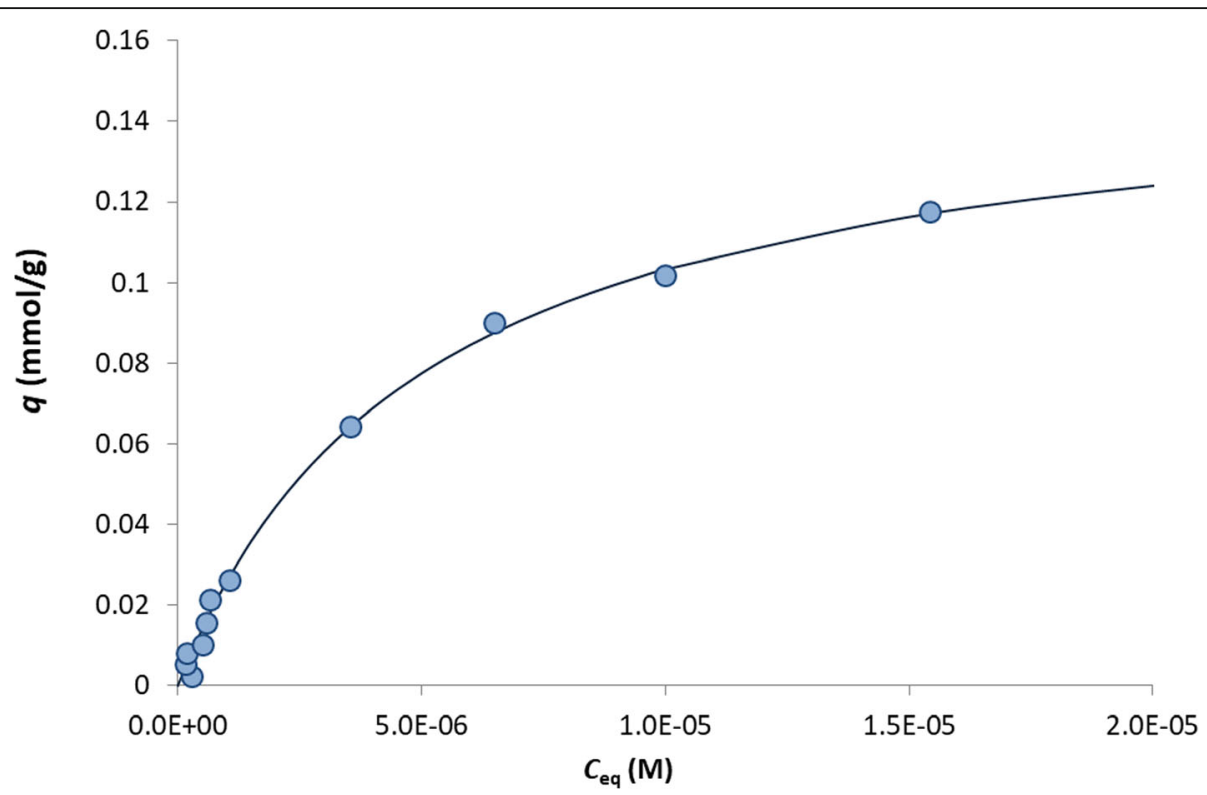

Fig. 1 Sorption isotherm of EBT on the CC. $w=0.02 \mathrm{~g} ; \mathrm{V}=25 \mathrm{~mL}$ at $\mathrm{pH}=10 ; \mathrm{T}=25^{\circ} \mathrm{C}$. The continuous line is the fitting according to the Langmuir equation (see parameters in Table 1)

\section{Actual samples}

For water hardness, we sampled tap waters in the district of Pavia (Lombardia, Italy). Before sampling, water was left flowing for 15-20 min and then collected in $1 \mathrm{~L}$ polyethylene bottle. Commercial mineral water (SANG EMINI-Italy, mineral water rich in mineral salts, and especially in calcium(II) was also analyzed. Before analysis, all samples were stored at a low temperature (e.g., $4{ }^{\circ} \mathrm{C}$ ).

The following dietary supplements of $\mathrm{Co}(\mathrm{II}), \mathrm{Ni}(\mathrm{II})$, and $\mathrm{Zn}(\mathrm{II})$ were analyzed as delivered or after suitable dilution with MilliQ water: Fisiosol5 $5^{\circ}$ (Specchiasol, Italy); Oligosol $^{\odot}$ (Labcatal, France) Catalitic ${ }^{\ominus}$ (Cemon, Italy); Gammadyn $^{\odot}$ (Unda, Belgium). Each product contains a different quantity of gluconate salts; Table 5 reports, in the second column, the metal concentrations declared on the packaging $\left(c_{\mathrm{d}}\right)$.

\section{Results and discussion}

\section{Characterization of Colour Catcher product}

The bare material was characterized by ATR-IR and EDX spectroscopies and by SEM.

The ATR-IR spectrum reveals a polymeric structure of the material, with bands below $1000 \mathrm{~cm}^{-1}$. Several bands of O-H stretching in the range of $3200-3600 \mathrm{~cm}^{-1}$, and C-O stretching at around 1050, 1103, and $1159 \mathrm{~cm}^{-1}$, could be attributed to ester groups. A band at 1735 $\mathrm{cm}^{-1}$ may be assigned to carboxylic groups. Other minor bands can be related to a reduced number of $\mathrm{C}-$ C double bonds (see ESI, Additional file 1: Figure S1).

The EDX analysis confirms the presence of $\mathrm{C}, \mathrm{O}$, and a slight amount of $\mathrm{Cl}$ and $\mathrm{Na}$, probably present as $\mathrm{Na}^{+}$ and $\mathrm{Cl}^{-} . \mathrm{Cl}$ is present at about $1.4 \%$, which corresponds to $0.4 \mathrm{mmol} / \mathrm{g}$ (see ESI, Additional file 1: Figure S2). SEM images show the fibre composition of the sheets (see ESI, Additional file 1: Figure S3).

\section{Sensor preparation}

With preliminary experiments, we established the best $\mathrm{pH}$ value for the sorption of each dye on the CC. After that, at those $\mathrm{pH}$, we built sorption isotherms for determining the maximum sorption capacity of $\mathrm{CC}$ toward each dye.

As an example, the graph presented in Fig. 1 represents the sorption isotherm of EBT on $\mathrm{CC}$ at $\mathrm{pH}=10$. Langmuir equation gave the best fitting for all dyes; these results are summarized in Table 1.

We also performed kinetic experiments to establish the suitable timing for obtaining stable and reproducible sensors.

As an example, Fig. 2 shows the kinetic sorption profile of PAN on $\mathrm{CC}$, at $\mathrm{pH} 11$. The stirring of the samples was kept constant on a shaking plate. The

Table 1 Sorption isotherms and kinetics of EBT and PAN on CC. Parameters of the fitting according to the Langmuir equation. The number in parenthesis is the standard uncertainty on the least significant digit. The last column shows the time required to reach the equilibrium $\left(t_{\mathrm{e}}\right)$ between $C \mathrm{C}$ and each dye

\begin{tabular}{lllll}
\hline & $\mathrm{pH}$ & $K_{\mathrm{L}}\left(\mathrm{M}^{-1}\right)$ & $q_{\max }\left(\mathrm{mmol} \mathrm{g}^{-1}\right)$ & $t_{e}(\mathrm{~h})$ \\
\hline EBT & 10 & $2.0(2) \cdot 10^{5}$ & $0.155(7)$ & 2 \\
PAN & 11 & $8.0(3) \cdot 10^{4}$ & $0.011(2)$ & 10 \\
\hline
\end{tabular}




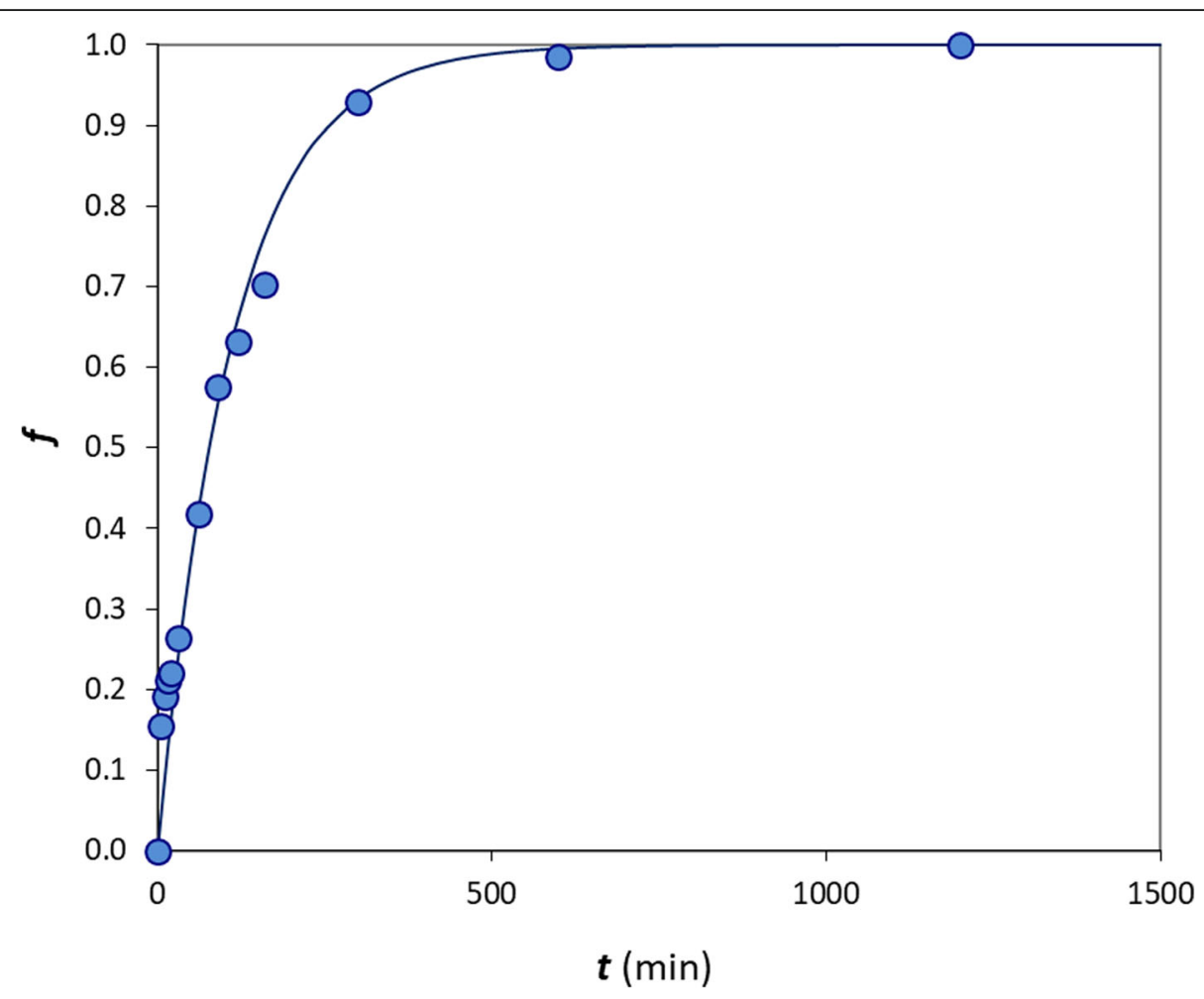

Fig. 2 Kinetic profiles of PAN on CC. CC pieces of $2 \times 2.5 \mathrm{~cm}(0.03 \mathrm{~g})$ put in contact with $10 \mathrm{~mL}$ of $50 \mu \mathrm{M}$ PAN solutions at pH $=11 \mathrm{for}$ different contact times. The black line is the fitting according to a film diffusion limiting process model

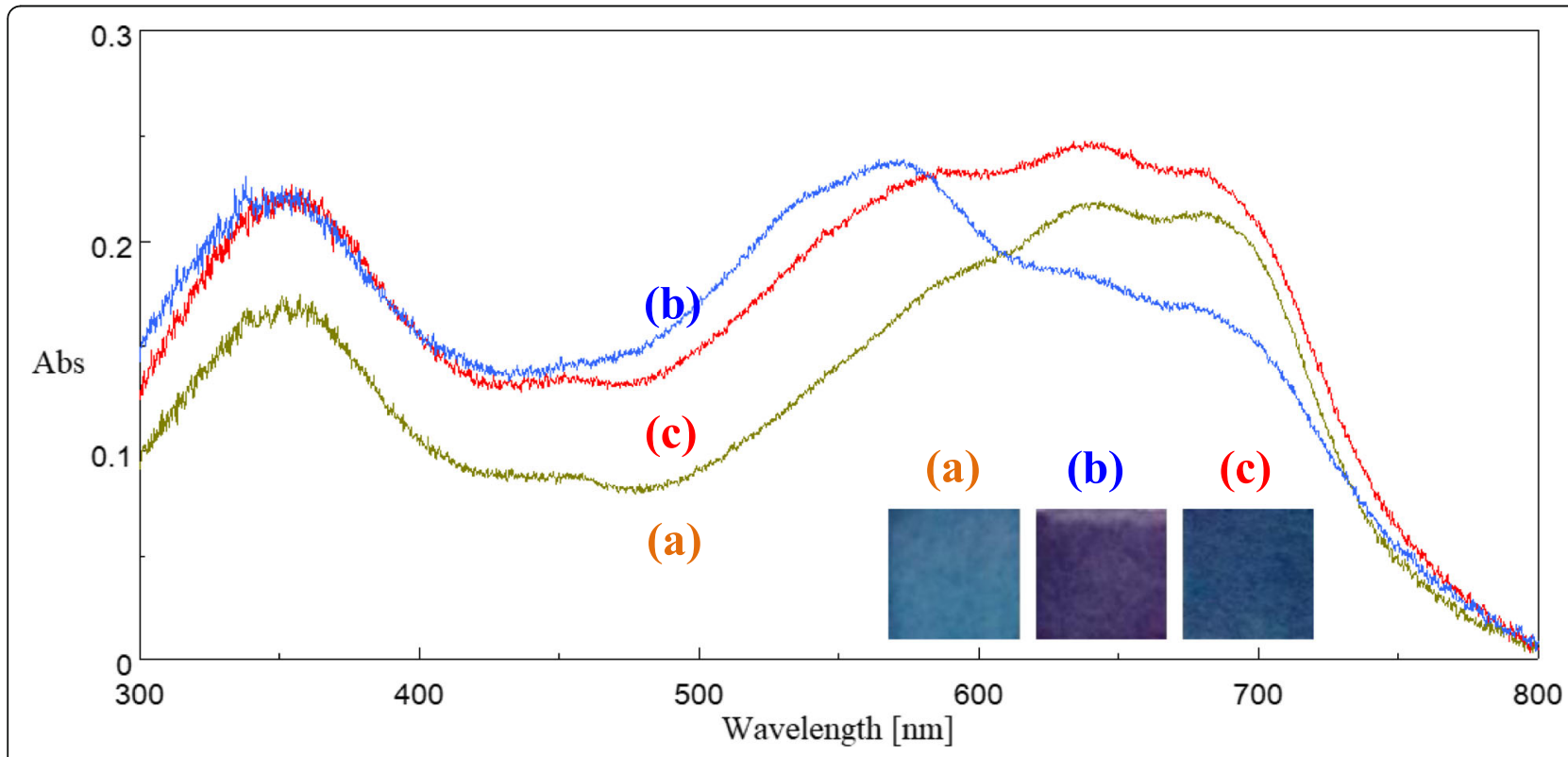

Fig. 3 UV-vis spectra and images of EBT-CC before (a) and after equilibration in Mg(II) solution (b) or Ca(II) solution (c) 


\section{Model with 6 Comp.}

\section{Model with 6 Comp.}

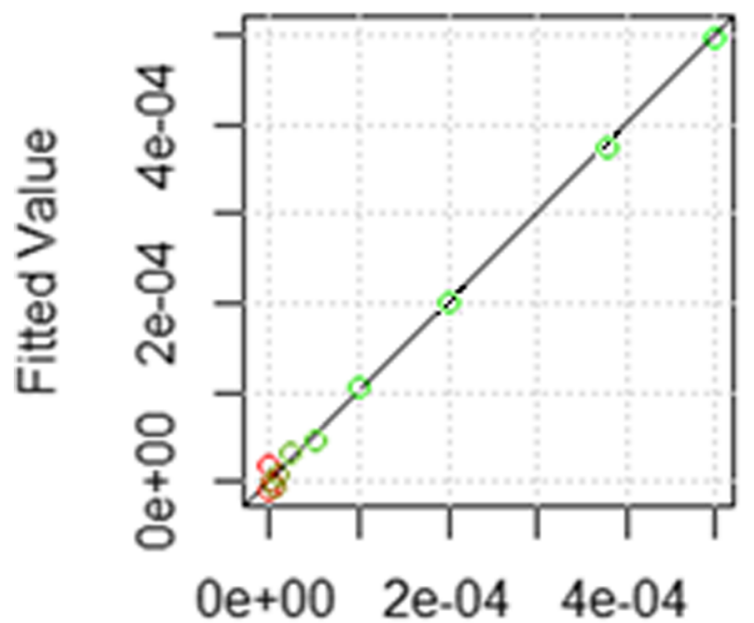

Experimental Value

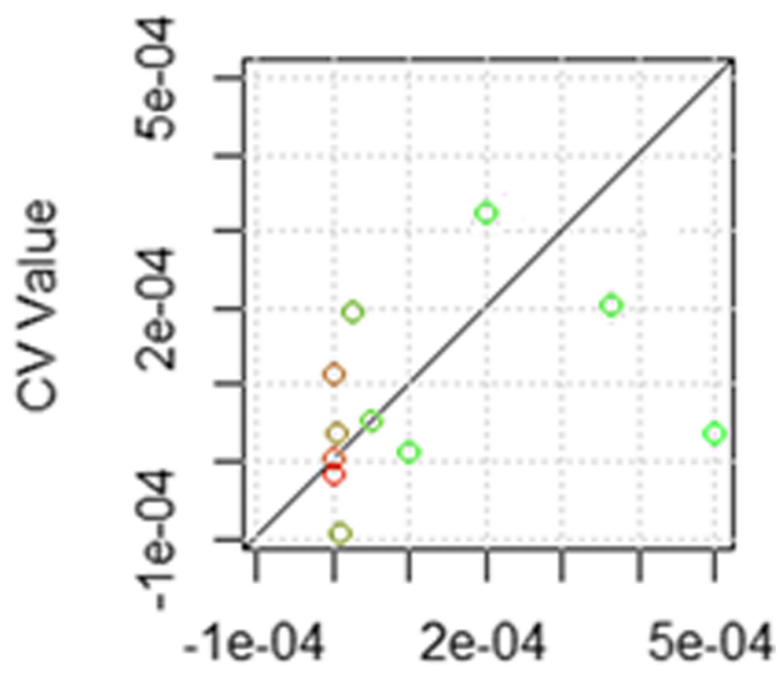

Experimental Value

Fig. 4 Software output for the PLS regression model, based on 6 latent variables, for the Mg(II) determination by EBT-CC sensor. The different colours refer to two different experiments at low (red) and at high (green) metal ion concentration. (1) Comparison of the experimental points with the points recalculated from the model; (2) the same comparison but in conditions of cross-validation. This plot assesses the variability of the estimated parameters and its effect on the prediction

homogeneous particle diffusion model, HPDM (Alberti 2012), was applied for data fitting; the profile seems well described by a film diffusion model, but this is purely a qualitative indication. For assessing which of the kinetic process limits the sorption of the dye, we have to perform other experiments, but it falls outside the purposes of this paper. Table 1, last column, shows the time required to reach the equilibrium between $\mathrm{CC}$ and each dye.

Once the procedure for the EBT-CC setup was established, we studied the sorption of $\mathrm{Ca}(\mathrm{II})$ and $\mathrm{Mg}(\mathrm{II})$ on the prepared sensor.

These two divalent cations form stable complexes with the ligand (EBT) in solution, so we chose to refer to this property for the development of a colourimetric sensor. We decided to work with solutions buffered at a $\mathrm{pH}$ of

Table 2 Composition of the solutions used to build the PLS model for the water's hardness

\begin{tabular}{lllll}
\hline & $\mathrm{Ca}(\mathrm{II})(\mathrm{mg} / \mathrm{L})$ & $\mathrm{Mg}(\mathrm{II})(\mathrm{mg} / \mathrm{L})$ & $\mathrm{M}$ & ${ }^{\circ} \mathrm{F}$ \\
\hline Very soft & 6 & 1 & $1.9 \times 10^{-4}$ & $\mathbf{2}$ \\
Soft & 18 & 4 & $6.1 \times 10^{-4}$ & $\mathbf{6}$ \\
Medium & 30 & 6 & $1.0 \times 10^{-3}$ & $\mathbf{1 0}$ \\
Hard & 45 & 9 & $1.5 \times 10^{-3}$ & $\mathbf{1 5}$ \\
Very hard & 70 & 15 & $2.4 \times 10^{-3}$ & $\mathbf{2 4}$ \\
Extremely hard & 100 & 20 & $3.3 \times 10^{-3}$ & $\mathbf{3 3}$ \\
\hline
\end{tabular}

about 10 since it is well known that the sorption of the ligand on the $\mathrm{CC}$ material and the complexation of $\mathrm{Ca}(\mathrm{II})$ and $\mathrm{Mg}(\mathrm{II})$ occurs optimally at this basic $\mathrm{pH}$.

The EBT-CC sensors took different colours after contact with $\mathrm{Ca}(\mathrm{II})$ or $\mathrm{Mg}(\mathrm{II})$ solutions that can be related to the nature and concentration of the cation. Figure 3 shows the spectra and the images of EBT-CC before and after equilibration, respectively, with $\mathrm{Mg}(\mathrm{II})$ and $\mathrm{Ca}(\mathrm{II})$ solutions.

$\mathrm{Mg}(\mathrm{II})$ was quickly sorbed on the EBT-CC since the time needed to reach the equilibrium is about $10 \mathrm{~min}$; on the other hand, $\mathrm{Ca}$ (II) needed about $2 \mathrm{~h}$ to reach equilibrium with the solid phase.

For each of the two metal ions, experiments were carried out to study the sorption as a function of the analyte concentration. Experimentally, in 10 glass tubes with stopper, all equal clippers of EBT-CC were equilibrated for $2 \mathrm{~h}$, at room temperature, under stirring on a shaking plate, with $25 \mathrm{~mL}$ of ammonium buffer solution at $\mathrm{pH}=10$, containing an amount of cation varying from 0 at $0.5 \mathrm{mM}$. After equilibration, the UV-vis spectra of EBT-CCs were recorded. As aforementioned, we used the partial least squares (PLS) analysis to find the most suitable model able to correlate the spectra of EBT-CC with the cation concentrations.

As an example, Fig. 4 reports the data processing with PLS of the experiments performed for the system 


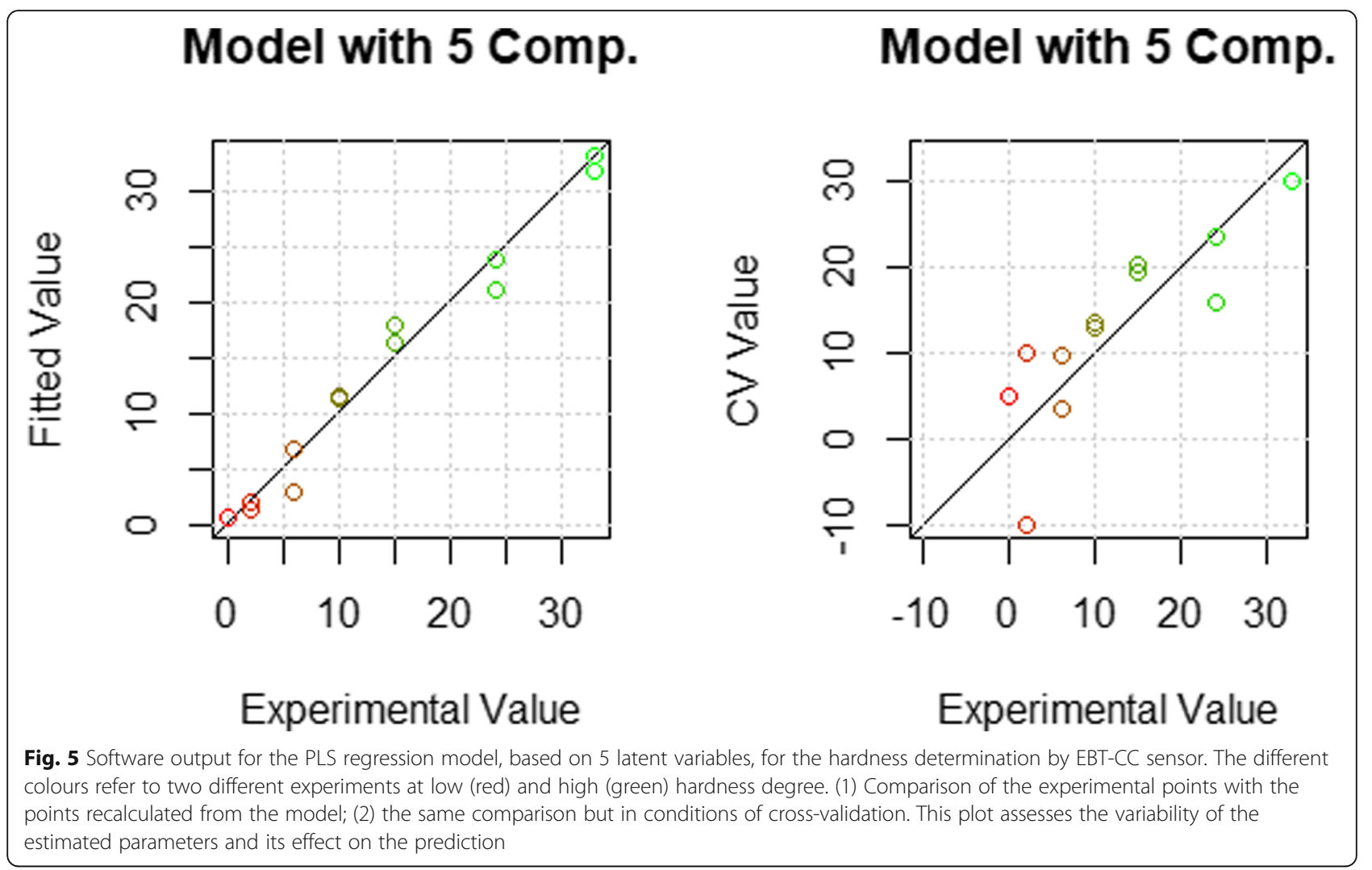

$\mathrm{Mg}(\mathrm{II}) / \mathrm{EBT}-\mathrm{CC}$. The reasonably good fitting obtained allows stating that the model is valid to interpret the experimental data, but from the CV plot, the significant errors, especially at high concentrations, mean that the results can be affected by imprecision.

Owing to the weakness of the previous model, we decided to move on water hardness determination. So we submitted full UV-vis spectra of EBT-CC, after equilibration with waters at different hardness, to a new PLS analysis. The training set of samples, required to build up the model, was obtained contacting EBT-CC sensors with synthetic solutions at a different degree of hardness, spanning from very soft to very hard waters (from 0 to $\left.33^{\circ} \mathrm{F}\right)$. The samples' description and the PLS results are reported in Table 2 and Fig. 5.

Differently from the previous model, in this case, a reasonable prediction of water hardness can be anticipated given the less scattered $\mathrm{CV}$ plot.

About the limit of detection (LOD) and limit of quantification (LOQ), they were obtained analyzing 10 independent blank solutions, and they were computed as respectively $3 \times \sigma_{\mathrm{B}}$ and $10 \times \sigma_{\mathrm{B}}$, where $\sigma_{\mathrm{B}}$ is the standard deviation of the concentrations predicted by the PLS models. The values obtained, expressed as water hardness $\left({ }^{\circ} \mathrm{F}\right)$, were $\mathrm{LOD}=0.5^{\circ} \mathrm{F}$ and LOQ $=1.7$ ${ }^{\circ} \mathrm{F}$. Linearity is between 0 and $40^{\circ} \mathrm{F}$.
For evaluating the predictive ability of the model, some real samples were used as a test set. In the following Table 3, the hardness values determined with the standard method of titration with EDTA and those predicted by the PLS model, for a tap water sample and bottled mineral water, are shown. As can be seen, the PLS model was able to predict rather well the hardness of the water samples examined: indeed, the prediction error is less than $15 \%$.

Since the metal ion concentrations in the real samples here analyzed were in good agreement with those predicted by the PLS models, we can confirm that not other cations interfere in these determinations.

To complete the work, we tested the EBT-CC sensor in solutions containing possible interfering cations, in particular, $\mathrm{Cu}(\mathrm{II}) ; \mathrm{Mn}(\mathrm{II}) ; \mathrm{Zn}(\mathrm{II})$ and $\mathrm{Fe}(\mathrm{III})$, which are all well known to react with EBT and induce a colour change. At different portions of $25 \mathrm{~mL}$ of the previously

Table 3 Prediction of hardness values in water samples by the PLS model, from UV-vis spectra measurements, using EBT-CC

\begin{tabular}{llll}
\hline & $\operatorname{Hardness}\left({ }^{\circ} \mathrm{F}\right)$ & Fit PLS $\left({ }^{\circ} \mathrm{F}\right)$ & $e \%$ \\
\hline Tap water & 13.5 & 11.5 & -14.8 \\
SANGEMINI water diluted 2 times & 43.5 & 47.6 & 9.4 \\
SANGEMINI water diluted 4 times & 21.9 & 23.1 & 5.4 \\
\hline
\end{tabular}


prepared synthetic water at a medium hardness degree $10{ }^{\circ} \mathrm{F}$, we added different quantities of the supposed interfering cations, spanning from 0 to $0.1 \mathrm{mM}$, at $\mathrm{pH}=$ 10. After contact with the EBT-CC sensors, the UV-vis spectra were registered and submitted to the PLS model as an external dataset. For all samples, the predicted hardness values did not differ significantly from $10{ }^{\circ} \mathrm{F}$, with the average value of all these samples being $10.3 \pm$ $0.6^{\circ} \mathrm{F}$.

\section{PAN-CC sensor for $\mathrm{Co}(\mathrm{II}), \mathrm{Ni}(\mathrm{II})$, and $\mathrm{Zn}$ (II) determination}

The PAN-AC optodes were prepared by immobilizing the receptor, PAN, on clippings of the Colour Catcher'. PAN-AC devices showed excellent mechanical properties and did not release the ligand in aqueous solution.

Preliminarily, we studied the sorption profile of PAN on the CC clippings as a function of the solution $\mathrm{pH}$, registering the UV-vis spectrum of the solid phase after equilibration. From solutions at $\mathrm{pH}$ higher or equal to 10 , an evident and intense peak at $465 \mathrm{~nm}$ appeared; on the contrary, at a lower $\mathrm{pH}$, the spectra showed broadband. So, it was decided to work at a pH higher than 10 since the peak is most clear and evident.

Having so defined the best $\mathrm{pH}$ for the sorption of the PAN on the CC, we studied the sorption of the three selected metal cations: $\mathrm{Co}(\mathrm{III}), \mathrm{Ni}(\mathrm{II})$, and $\mathrm{Zn}(\mathrm{II})$ on the PAN-CC, equilibrating the solid phase with metal cations solutions at $\mathrm{pH}=10$ in ammonium buffer. Figure 6 shows the spectra and the images of the PAN-AC sensor before and after contact with the metal ion solutions.

About the kinetic, the time required to reach the equilibrium when PAN-CC was contacted with the three transition-metal salt solutions is rather long, as it took about $12 \mathrm{~h}$.

Langmuir model described well the sorption isotherms for all ions, obtaining a maximum sorption capacity, $q_{\text {max }}$, of about $0.01 \mathrm{mmol} / \mathrm{g}$ at $\mathrm{pH}=10$.

Finally, we developed a model for simultaneously assessing, in an unknown sample, the concentration of $\mathrm{Co}(\mathrm{II}), \mathrm{Ni}(\mathrm{II})$, and $\mathrm{Zn}(\mathrm{II})$.

UV-vis spectra of the solid phase under quantitative adsorption conditions $(\mathrm{pH}=10$, overnight loading of cations, and excess of active sites of the solid phase) were registered using the entire spectrum for the analysis. Since the methodology required the planning of a suitable "training set," we prepared it by mixing standard solutions of the three cations, at different concentrations, covering the experimental domain symmetrically by applying an experimental design. For this work, we chose the experimental design with five concentration levels, based on multilevel partial factorial design (MPFD) (Brerenton 1997). In the book of Brerenton (Brerenton 1997), a proper guideline for designing a series of multicomponent mixtures for calibration is reported. Table 4 presents the plan of the experiments, obtained by MPFD design with five concentration levels. The satisfactory ability of PLS to model the experimental data is evident from the rather good agreement between the measured and fitted values, as shown in Fig. 7.

For the $\mathrm{Zn}(\mathrm{II})$, the dispersion of the data is higher than that of the other two cations, probably due to the considerable ease of contamination during the experiments in the presence of ubiquitous cations as $\mathrm{Zn}(\mathrm{II})$, resulting in poorly accurate determinations.

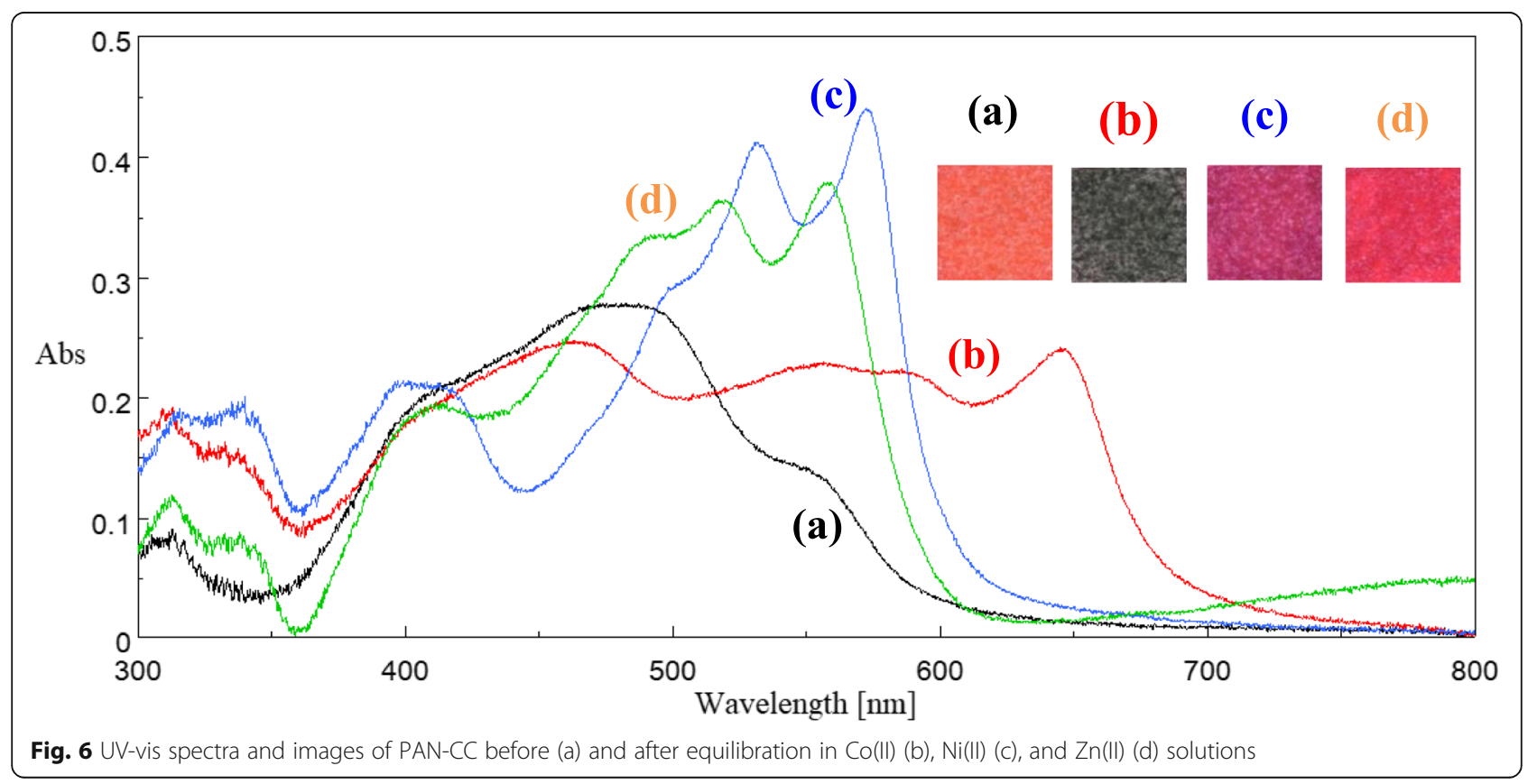


Table 4 MPFD experimental design: 5 levels for 3 components. $V=25 \mathrm{~mL}$ of ammonia buffer solution at pH $=10$ and $0.033 \mathrm{~g}$ of PAN-CC

\begin{tabular}{|c|c|c|c|c|c|}
\hline \multicolumn{2}{|c|}{ Variable levels } & \multicolumn{4}{|c|}{ Design of experiments } \\
\hline Level & $c(\mu M)$ & & {$[\mathrm{Co}]$} & {$[\mathrm{Ni}]$} & {$[\mathrm{Zn}]$} \\
\hline-2 & 0 & 1 & 0 & 0 & 0 \\
\hline-1 & 3.5 & 2 & 0 & -2 & -1 \\
\hline 0 & 4.5 & 3 & -2 & -1 & -2 \\
\hline 1 & 5.5 & 4 & -1 & -2 & 2 \\
\hline \multirow[t]{21}{*}{2} & 7 & 5 & -2 & 2 & 2 \\
\hline & & 6 & 2 & 2 & 0 \\
\hline & & 7 & 2 & 0 & -1 \\
\hline & & 8 & 0 & -1 & 2 \\
\hline & & 9 & -1 & 2 & -1 \\
\hline & & 10 & 2 & -1 & 1 \\
\hline & & 11 & -1 & 1 & 1 \\
\hline & & 12 & 1 & 1 & 0 \\
\hline & & 13 & 1 & 0 & 2 \\
\hline & & 14 & 0 & 2 & 1 \\
\hline & & 15 & 2 & 1 & 2 \\
\hline & & 16 & 1 & 2 & -2 \\
\hline & & 17 & 2 & -2 & -2 \\
\hline & & 18 & -2 & -2 & 0 \\
\hline & & 19 & -2 & 0 & 1 \\
\hline & & 20 & 0 & 1 & -2 \\
\hline & & 21 & 1 & -2 & 1 \\
\hline & & 22 & -2 & 1 & -1 \\
\hline & & 23 & 1 & -1 & -1 \\
\hline & & 24 & -1 & -1 & 0 \\
\hline & & 25 & -1 & 0 & -2 \\
\hline
\end{tabular}

The limit of detection (LOD) and limit of quantification (LOQ) are calculated as respectively $3 \times \sigma_{\mathrm{B}}$, and 10 $\times \sigma_{B}$, where $\sigma_{B}$ is the standard deviation of the concentrations for blank solutions (10 replicates) obtained from the PLS models. The values are in the following summarized: $\mathrm{Co}(\mathrm{II}), \mathrm{LOD} 0.80 \mu \mathrm{M}$, and LOQ $2.7 \mu \mathrm{M}$; Ni(II), LOD $0.33 \mu \mathrm{M}$, and LOQ $1.1 \mu \mathrm{M}$; Zn(II), LOD $0.81 \mu \mathrm{M}$, and LOQ $2.7 \mu \mathrm{M}$. The linearity range is from 0 to 10 $\mu \mathrm{M}$ for all cations.

The regression model is always first tested with a cross-validation procedure on the training set, and then, on an external data set, called the test set. A series of independent samples of the investigated cations were prepared for this purpose. As an additional validation test, we analyzed four dietary supplements of $\mathrm{Co}(\mathrm{II}), \mathrm{Ni}(\mathrm{II})$, and $\mathrm{Zn}(\mathrm{II})$. Table 5 summarizes the results. Comparing the concentrations declared on the packaging with the predicted values by the PLS models, the differences are modest, being, in any case, less than $15 \%$. Based on these results, the PAN-CC sensor seems promising for the simultaneous determination of $\mathrm{Co}(\mathrm{II}), \mathrm{Ni}(\mathrm{II})$, and $\mathrm{Zn}(\mathrm{II})$.

\section{Conclusions}

We developed optical sensors by immobilization of two classical dyes, Eriochrome Black T (EBT) and 1-(2-pyridylazo)-2-naphthol (PAN), on an inert solid support, i.e., a product of the washing powder market known as Colour Catcher ${ }^{\ominus}$. The devices obtained are named EBT$\mathrm{CC}$ and PAN-CC, and they acted as excellent sensors, respectively, for $\mathrm{Ca}(\mathrm{II})$ and $\mathrm{Mg}(\mathrm{II})$, and for $\mathrm{Co}(\mathrm{II}), \mathrm{Ni}(\mathrm{II})$, and $\mathrm{Zn}(\mathrm{II})$.

These sensors were easily prepared by immersion of portions of $\mathrm{CC}$ in aqueous solutions of the dyes. For each receptor, we have found the best experimental conditions for the sensor's preparation.

These devices assumed different colours after equilibration with solutions of the analytes, and this property was used to develop optical sensors since the colour 
Model with 7 Comp.

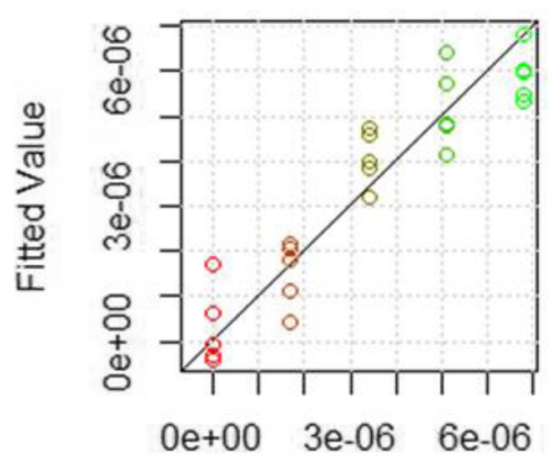

Experimental Value

Model with 9 Comp.

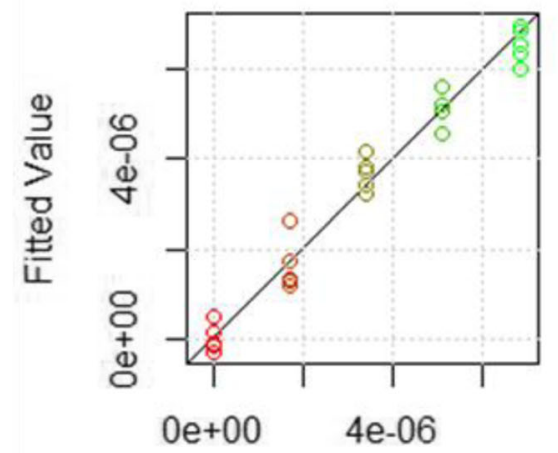

Experimental Value

Model with 5 Comp.

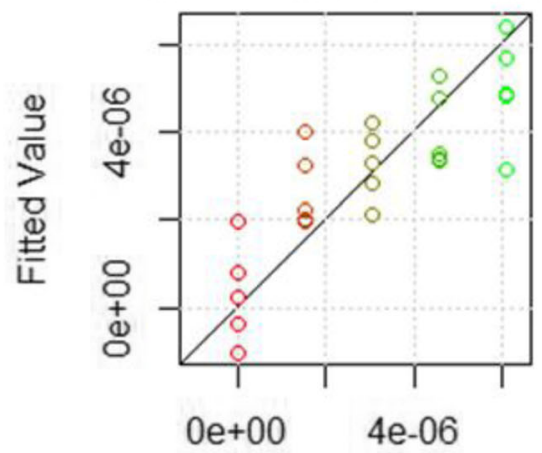

Experimental Value
Model with 7 Comp.

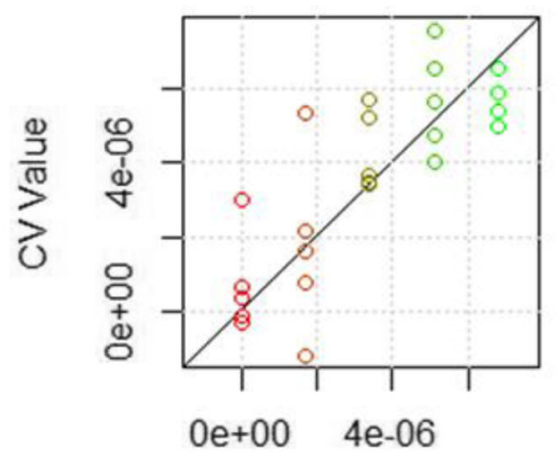

Experimental Value

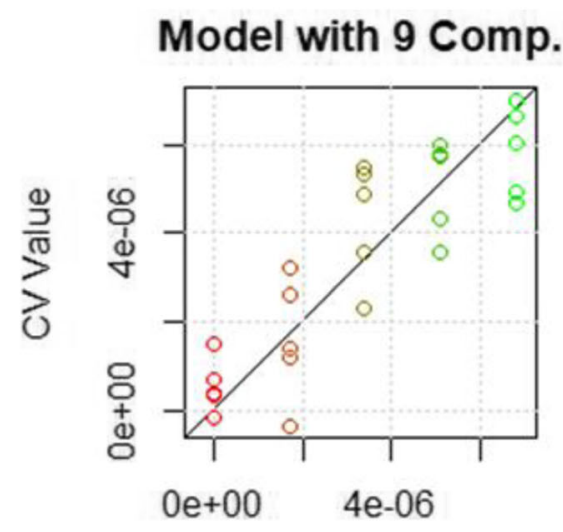

Experimental Value

Model with 5 Comp.

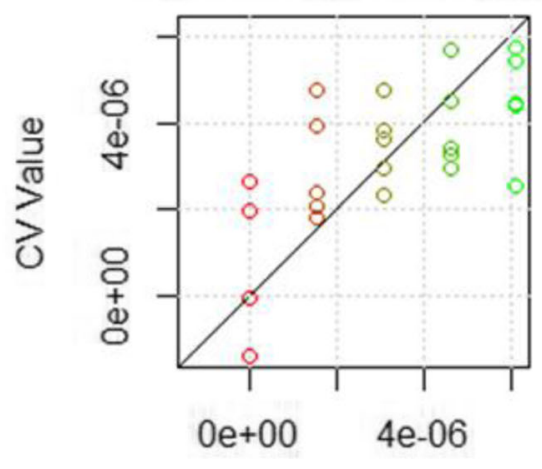

Experimental Value

Fig. 7 Software output for the PLS regression model: Co(II), Ni(II), and Zn(II) on the PAN-CC sensor. a Model for Co(II); b model for Ni(II); $\mathrm{C}$ model for $Z n(I I)$. The different colours refer to five replicates at different metal ion concentration. (1) Comparison of the experimental points with the points recalculated from the model; (2) the same comparison but in the conditions of cross-validation. This plot assesses the variability of the estimated parameters and its effect on the prediction 
Table 5 Prediction of $\mathrm{Co}(I), \mathrm{Ni}(I)$, and Zn(II) values in four commercial oligomineral supplements by the PLS model, from UV-vis spectra measurements, using PAN-CC

\begin{tabular}{|c|c|c|c|c|}
\hline$\overline{\text { Fisiosol }^{\circ}}$ & $c_{\mathrm{d}}(\mathrm{mg} / 2 \mathrm{~mL})$ & $c_{d}(\mathrm{mM})$ & $c_{m}(m M)$ & $e \%$ \\
\hline $\mathrm{Co}(\mathrm{II})$ & 0.0726 & 0.616 & $0.55(1)$ & -11 \\
\hline $\mathrm{Ni}(I I)$ & 0.0726 & 0.618 & $0.68(9)$ & 10 \\
\hline $\mathrm{Zn}(I)$ & 0.0674 & 0.515 & $0.48(8)$ & -7 \\
\hline Oligosol $^{\circ}$ & $c_{d}(m g / 2 m L)$ & $c_{d}(m M)$ & $c_{m}(m M)$ & $e \%$ \\
\hline $\mathrm{Co}(I I)$ & 0.0726 & 0.616 & $0.54(8)$ & -12 \\
\hline $\mathrm{Ni}(I I)$ & 0.0726 & 0.618 & $0.7(2)$ & 13 \\
\hline $\mathrm{Zn}(I I)$ & 0.0674 & 0.515 & $0.45(1)$ & -13 \\
\hline Catalitic & $c_{\mathrm{d}}(\mathrm{mg} / 2 \mathrm{~mL})$ & $c_{d}(m M)$ & $c_{m}(m M)$ & $e \%$ \\
\hline $\mathrm{Co}(I I)$ & 0.062 & 0.526 & n.d. & / \\
\hline $\mathrm{Ni}(I I)$ & 0.088 & 0.750 & $0.8(7)$ & 6 \\
\hline $\mathrm{Zn}(I I)$ & 0.314 & 2.4 & $2.1(4)$ & -13 \\
\hline Gammadyn & $c_{d}(m g / 2 m L)$ & $c_{d}(m M)$ & $c_{m}(m M)$ & $e \%$ \\
\hline $\mathrm{Co}(I I)$ & 0.073 & 0.619 & n.d. & / \\
\hline $\mathrm{Ni}(I I)$ & 0.073 & 0.622 & $0.6(3)$ & -3 \\
\hline $\mathrm{Zn}(I I)$ & 0.067 & 0.512 & $0.5(3)$ & 1 \\
\hline
\end{tabular}

$c_{\mathrm{d}}$ concentration declared on the packaging, $c_{\mathrm{m}}$ concentration predicted by the PLS model

variation can be correlated with the nature and the concentration of the analyte sorbed.

For analytical applications, it is fundamental to provide a model that correlates the signal (the UV-vis spectrum of the sensor after equilibration with the analyte solutions) and the concentration of the analytes. To this end, we decided to apply a chemometric tool: the multivariate regression PLS (partial least squares regression).

The models obtained proved their worth in predicting the concentrations of the analytes in aqueous, synthetic, and actual samples. The results obtained are promising, and other experiments are ongoing for improving the performance of these optical sensors.

\section{Supplementary information}

Supplementary information accompanies this paper at https://doi.org/10. 1186/s40543-020-00221-x.

Additional file 1: Figure S1. ATR-IR spectrum of CC. Figure S2. SEM images with different magnification and the corresponding EDX analysis. Figure S3. Electronic microscope imagines of the bare Colour Catcher at different magnification order

\section{Abbreviations}

EBT: Eriochrome Black T; PAN: 1-(2-Pyridylazo)-2-naphthol; CC: Colour Catcher; ; EBT-CC: Optical sensor based on CC functionalized with EBT; PANCC: Optical sensor based on CC functionalized with PAN; PLS: Partial least squares regression (chemometric tools); CAT: Chemometric Agile Tool, Rbased chemometric software; AAS: Atomic absorption spectroscopy; AFS: Atomic fluorescence spectroscopy; ICP-MS: Inductively coupled plasmamass spectroscopy; ICP-OES: Inductively coupled plasma-optical emission spectroscopy; FT-IR: Fourier transform infrared spectroscopy; ATR: Attenuated total reflectance; EDX: Energy-dispersive X-ray spectroscopy; SEM: Scanning electron microscope

\section{Acknowledgements}

We acknowledge Prof. Chiara Milanese (Hydrogen Lab, University of Pavia) for IR, EDX, and SEM measurements and PhD Simone Marchetti and lab 3D@UniPV (Virtual Modelling and Additive Manufacturing for Advanced Materials, University of Pavia) for the film holder realization.

\section{Authors' contributions}

The experimental part of the work has been carried out by Prof. Giancarla Alberti, Dr Lisa Rita Magnaghi, and Dr Camilla Zanoni. The manuscript has been written by Prof. Giancarla Alberti and Prof. Raffaela Biesuz. The author(s) read and approved the final manuscript.

\section{Funding}

Funds are provided from FAR (Fondi Ateneo Ricerca) of the University of Pavia.

\section{Availability of data and materials}

All data are presented in the manuscript.

Ethics approval and consent to participate

Not applicable

\section{Consent for publication}

Not applicable

\section{Competing interests}

We declare non-financial competing interests.

Received: 4 October 2019 Accepted: 11 June 2020

Published online: 20 July 2020

\section{References}

Alberti G, Amendola V, Pesavento M, Biesuz R. Beyond the synthesis of novel solid phases: review on modelling of sorption phenomena. Coord Chem Rev. 2012;256:28-45. https://doi.org/10.1016/j.ccr.2011.08.022.

Alberti G, Quattrini F, Colleoni R, Nurchi VM, Biesuz R. Deferoxamine-paper for iron(III) and vanadium(V) sensing. Chem Pap. 2015;69(8):1024-32. https://doi. org/10.1515/chempap-2015-0112.

Alberti G, Re S, Tivelli AMC, Biesuz R. Smart sensory materials for divalent cations: a dithizone immobilized membrane for optical analysis. Analyst. 2016;141: 6140-8. https://doi.org/10.1039/C6AN01560C. 
Berlina AN, Zherdev AV, Dzantiev BB. Progress in rapid optical assays for heavy metal ions based on the use of nanoparticles and receptor molecules. Microchim Acta. 2019;186:172. https://doi.org/10.1007/s00604-018-3168-9.

Biesuz R, Emma G, Milanese C, Dacarro G, Taglietti A, Nurchi VM, Alberti G. Novel DFO SAM on mesoporous silica for iron sensing. Part I. Synthesis optimization and characterization of the material. Analyst. 2014;139:3932-9. https://doi.org/10.1039/C4AN00179F.

Biesuz R, Santos MA, Nurchi VM, Alberti G. Development of a sensor for trivalent iron: AHP fixed on mesoporous silica. New J Chem. 2018;42:15237-44. https://doi.org/10.1039/C8NJ00869H.

Brerenton R. Multilevel multifactor designs for multivariate calibration. Analyst 1997;122:1521-2. https://doi.org/10.1039/A703654J.

Duarte K, Justino CIL, Freitas AC, Gomes AMP, Duarte AC, Rocha-Santos TAP. Disposable sensors for environmental monitoring of lead, cadmium and mercury. Trac-Trend Anal Chem. 2015;64:183-90. https://doi.org/10.1016/j. trac.2014.07.006.

Gerlach RW, Kowalski BR, Wold HOA. Partial least-squares path modeling with latent variables. Anal Chim Acta. 1979;112:417-21.

Gemperline P (2006) Practical guide to chemometrics, 2nd edition. Ed. Taylor \& Francis Group (USA) chapter 5, p.115.

Gogoi N, Barooah M, Majumdar G, Chowdhury D. Carbon dots rooted agarose hydrogel hybrid platform for optical detection and separation of heavy metal ions. ACS Appl Mater Interfaces. 2015;7(5):3058-67. https://doi.org/10.1021/ am506558d.

Hassaninejad-Darzi KS, Torkamanzadeh M. Simultaneous UV-vis spectrophotometric quantification of ternary basic dye mixtures by partial least squares and artificial neural networks. Water Sci Technol. 2016;74(10): 2497-504. https://doi.org/10.2166/wst.2016.440.

Kaur B, Kaur N, Kumar S. Colorimetric metal ion sensors - a comprehensive review of the years 2011-2016. Coord Chem Rev. 2018;358:13-69. https://doi. org/10.1016/j.ccr.2017.12.002.

Kohavi R. A study of cross-validation and bootstrap for accuracy estimation and model selection. Proceedings of the XIV IJCAI. San Mateo, CA: Morgan Kaufmann. 1995;2(12):1137-43.

Li M, Goulsraa H, Al-Ogaidi I, Wu N. Nanostructured sensors for detection of heavy metals: a review. ACS Sustain Chem Eng. 2013;1(7):713-23. https://doi. org/10.1021/sc400019a.

Maruthupandy $\mathrm{M}$, et al. Synthesis of metal oxide nanoparticles (CuO and $\mathrm{ZnO}$ NPs) via biological template and their optical sensor applications. Appl Surf Sci. 2017;397:167-74. https://doi.org/10.1016/j.apsusc.2016.11.118.

Moirangthem M, Arts R, Merkx M, Schenning APHJ. An optical sensor based on a photonic polymer film to detect calcium in serum. Adv Funct Mater. 2016;26: 1154-60. https://doi.org/10.1002/adfm.201504534.

Ng S-M, Narayanaswamy R. Demonstration of a simple, economical and practical technique utilising an imprinted polymer for metal ion sensing. Microchim Acta. 2010;169:303-11. https://doi.org/10.1007/s00604-010-0357-6.

Sharma H, Kaur N, Singh A, Kuwar A, Singh N. Optical chemosensors for water sample analysis. J Mater Chem C. 2016;4:5154-94. https://doi.org/10.1039/ C6TC00605A.

Steinberg IM, Lobnik A, Wolfbeis OS. Characterisation of an optical sensor membrane based on the metal ion indicator Pyrocatechol Violet. Sens Actuators B Chem. 2003;90(1-3):230-5. https://doi.org/10.1016/S09254005(03)00033-9.

Sun Z, Cui G, Li H, Liu Y, Tian Y, Yan S. Multifunctional optical sensing probes based on organic-inorganic hybrid composites. J Mater Chem B. 2016;4: 5194-216. https://doi.org/10.1039/C6TB01468B.

Ullah N, Mansha M, Khan I, Qurashi A. Nanomaterial-based optical chemical sensors for the detection of heavy metals in water: recent advances and challenges. Trac-Trend Anal Chem. 2018;100:155-66.

Vallejos S, Muñoz A, García FC, Colleoni R, Biesuz R, Alberti G, García JM. Colorimetric detection, quantification and extraction of Fe(III) in water by acrylic polymers with pendant kojic acid motifs. Sens Actuators B-Chem. 2016;233:120-6. https://doi.org/10.1016/j.snb.2016.04.040.

Vuković J, Avidad MA, Capitán-Vallvey LF. Characterization of disposable optical sensors for heavy metal determination. Talanta. 2012;94:123-32. https://doi org/10.1016/j.talanta.2012.03.006

Yarur F, Macairan J-R, Naccache R. Ratiometric detection of heavy metal ions using fluorescent carbon dots. Environ Sci Nano. 2019;6:1121-30. https://doi. org/10.1039/C8EN01418C.

\section{Publisher's Note}

Springer Nature remains neutral with regard to jurisdictional claims in published maps and institutional affiliations.

\section{Submit your manuscript to a SpringerOpen ${ }^{\circ}$ journal and benefit from:}

- Convenient online submission

- Rigorous peer review

- Open access: articles freely available online

- High visibility within the field

- Retaining the copyright to your article

Submit your next manuscript at $\boldsymbol{\nabla}$ springeropen.com 